\title{
Surgical treatment for ossification of the posterior longitudinal ligament and the yellow ligament in the thoracic and cervico-thoracic spine
}

\author{
Kazuhiro Ido ${ }^{1}$, Katsuji Shimizu ${ }^{2}$, Hirokazu Iida ${ }^{1}$ and Takashi Nakamura ${ }^{1}$ \\ ${ }^{1}$ Department of Orthopaedic Surgery, Faculty of Medicine, Kyoto University; ${ }^{2}$ Department of Orthopaedic Surgery, \\ School of Medicine, Gifu University, Japan
}

\begin{abstract}
This study analyzed the postoperative results of surgical treatment for thoracic and cervicothoracic myelopathy caused by ossification of the posterior longitudinal ligaments (OPLL) or ossification of the yellow ligaments (OYL) in 22 patients using magnetic resonance imaging (MRI), myelography and computed tomography (CT).

Anterior procedures were performed in 11 patients for OPLL, while posterior approaches were adopted for the management of 11 patients for both OYL and OPLL combined with OYL lesions. Clinical symptoms were improved using both anterior and posterior techniques.

MRI and myelo-CT studies, which show the direction of cord compression, the form and extent of the lesion, and the degree of thoracic kyphosis, are very useful when the surgical procedure for OPLL and OYL in the thoracic and cervico-thoracic spine is selected.
\end{abstract}

Keywords: surgery; thoracic spine; cervico-thoracic spine; ossification of the posterior longitudinal ligament; ossification of the yellow ligament

\section{Introduction}

Thoracic myelopathy caused by ossification of the posterior longitudinal ligament (OPLL) or ossification of the yellow ligament (OYL) is rare in comparison with cervical myelopathy. However, several reports suggest that surgical management is the most effective treatment for thoracic myelopathy. ${ }^{1}$ These surgical procedures are not discussed in detail.

This study analyzes the postoperative results of anterior and posterior approaches to OPLL and OYL in the thoracic and cervico-thoracic spine. The objectives of this study are to evaluate which procedure is most useful for the treatment of OPLL and OYL in the thoracic and cervico-thoracic spine using magnetic resonance imaging (MRI), myelography and computed tomography (CT).

\section{Materials and methods}

Between 1981 and 1992, 36 patients had surgery for OPLL and OYL in the thoracic and cervico-thoracic spine. A 2 year follow-up was obtained in 22 of these individuals. Anterior procedures were performed in 11 patients, while posterior approaches were adopted for the remaining 11 (Tables 1 and 2). These 13 women and 9 men, with a mean age of 56, were followed for

Correspondence: K Ido, Department of Orthopaedic Surgery, Japanese Red Cross Society, Wakayama Medical Center, 4-20 Komatsubara-dori, Wakayama, 640, Japan an average of mean 56 months. In 11 patients, lesions involved the upper thoracic spine, eight occurred in the middle thoracic spine, and three in the lower thoracic spine.

Anterior procedures were performed in 11 patients with ventral compression only by OPLL. Upper thoracic lesions were treated in one patient, middle thoracic in eight, and lower thoracic in two patients. Anterior decompression and fusion was accomplished using a transthoracic approach in 10 patients and a median sternotomy in one. Following resection of the vertebral body, OPLL was shaved using the surgical airtome under the microscopic view. At the end of the decompression, a thin layer of OPLL was left floating on the dura. Autologous bone grafting was accomplished using fibula, iliac bone, or rib.

A laminectomy was completed in 11 other patients with OPLL (five patients) and OYL (four patients) of the upper thoracic spine, and combined OPLL and OYL lesions involving the upper (one patient) and lower thoracic spine (one patient). Anterior decompression through a posterior approach, shaving OPLL and posterior part of the vertebral body using surgical airtome after en bloc laminectomy and resection of the medial third of pedicle on both sides, was also performed in a patient with both OPLL and OYL involving the lower thoracic spine.

Pre- and postoperative clinical symptoms were assessed using the Japanese Orthopaedic Association (JOA) cervical myelopathy score system, omitting the 
Table 1 Summary of the clinical data (Anterior procedures)

\begin{tabular}{|c|c|c|c|c|c|c|c|c|c|c|}
\hline Age & $\operatorname{Sex}$ & $\begin{array}{l}\text { Fusion } \\
\text { level }\end{array}$ & $\begin{array}{c}\text { Form of } \\
\text { ossification }\end{array}$ & Approach & Bone graft & Symptoms & $\begin{array}{c}J O A \\
\text { pre-op. }\end{array}$ & $\begin{array}{c}\text { score } \\
\text { post-op. }\end{array}$ & $\begin{array}{c}\text { Follow-up } \\
\text { period }\end{array}$ & Complication \\
\hline 62 & $\mathrm{~F}$ & $\mathrm{C} 7-\mathrm{T} 4$ & moderate & midsternal & Fibula & improved & 7 & 10 & 2Y9Mo & RLNP \\
\hline 50 & $\mathrm{~F}$ & $\mathrm{~T} 2-\mathrm{T} 6$ & thick & transthoracic & Fibula & unchanged & 4 & 4 & 7Y9Mо & CSF fistula \\
\hline 61 & $\mathrm{~F}$ & $\mathrm{~T} 2-\mathrm{T} 6$ & thick & transthoracic & Rib & improved & 5 & 9 & 4Y11Mo & $(-)$ \\
\hline 55 & $\mathrm{~F}$ & $\mathrm{~T} 2-\mathrm{T} 7$ & moderate & transthoracic & Fibula & improved & 7 & 10 & 14Y2Mo & $(-)$ \\
\hline 64 & $\mathrm{~F}$ & T3-T5 & thick & transthoracic & Fibula & unchanged & 1 & 1 & $10 \mathrm{Y} 3 \mathrm{Mo}$ & $(-)$ \\
\hline 66 & $\mathrm{~F}$ & T3-T7 & thick & transthoracic & Fibula & improved & 2 & 3 & 2Y2Mo & $(-)$ \\
\hline 59 & $\mathrm{~F}$ & $\mathrm{~T} 4-\mathrm{T} 10$ & thick & transthoracic & Fibula & improved & 4 & 9 & 6Y10Mo & $(-)$ \\
\hline 48 & $\mathrm{~F}$ & $\mathrm{~T} 5-\mathrm{T} 7$ & thick & transthoracic & Fibula & improved & 6 & 9 & $6 \mathrm{Y} 10 \mathrm{Mo}$ & CSF fistula \\
\hline 51 & $\mathrm{~F}$ & T7-T9 & thick & transthoracic & Rib & improved & 2 & 3 & 2Y5Mo & $(-)$ \\
\hline 67 & $\mathrm{~F}$ & $\mathrm{~T} 7-\mathrm{T} 11$ & thick & transthoracic & Fibula & improved & 7 & 9 & $3 \mathrm{Y} 1 \mathrm{Mo}$ & CSF leakage \\
\hline 49 & M & $\mathrm{T} 12-\mathrm{L} 1$ & moderate & transthoracic & Fibula & improved & 9 & 10 & 6Y6Мo & $(-)$ \\
\hline
\end{tabular}

F: female; M: male; Y: year; Mo: month; RLNP: recurrent laryngeal nerve paralysis; CSF: cerebrospinal fluid

Table 2 Summary of the clinical data (Posterior procedures)

\begin{tabular}{|c|c|c|c|c|c|c|c|}
\hline Age & $\operatorname{Sex}$ & Level & $\begin{array}{l}\text { Patterns of } \\
\text { ossification }\end{array}$ & Symptoms & $\begin{array}{c}J O A \\
\text { pre-op. }\end{array}$ & $\begin{array}{c}\text { score } \\
\text { post-op. }\end{array}$ & $\begin{array}{l}\text { Follow-up } \\
\text { period }\end{array}$ \\
\hline 75 & $\mathrm{M}$ & $\mathrm{C} 3-\mathrm{T} 4$ & OPLL & improved & 4 & 8 & 3Y6Mo \\
\hline 60 & $\mathrm{~F}$ & $\mathrm{C} 1-\mathrm{T} 2$ & OPLL & improved & 9 & 11 & 3Y9Мо \\
\hline 57 & $\mathrm{~F}$ & $\mathrm{~T} 2-\mathrm{T} 4$ & OPLL & improved & 6 & 9 & 2Y1Mo \\
\hline 58 & $\mathrm{~F}$ & $\mathrm{C} 2-\mathrm{T} 3$ & OPLL & improved & 7 & 10 & 7Y6Mo \\
\hline 63 & M & $\mathrm{C} 1-\mathrm{T} 2$ & OPLL & improved & 5 & 10 & 2Y8Mo \\
\hline 56 & M & $\mathrm{C} 1-\mathrm{T} 3$ & OPLL(C) + OYL(T) & improved & 10 & 11 & $3 \mathrm{Y} 11 \mathrm{Mo}$ \\
\hline 75 & M & $\mathrm{C} 2-\mathrm{T} 3$ & OPLL $(\mathrm{C})+$ OYL $(\mathrm{T})$ & improved & 6 & 8 & $4 \mathrm{Y}$ \\
\hline 18 & $\mathrm{M}$ & $\mathrm{T} 2-\mathrm{T} 3$ & OYL & improved & 4 & 9 & $4 \mathrm{Y}$ \\
\hline 47 & M & $\mathrm{C} 1-\mathrm{T} 4$ & OPLL $(\mathrm{C})+\operatorname{OYL}(\mathrm{T})$ & improved & 6 & 8 & 6Y4Mo \\
\hline 49 & M & $\mathrm{C} 2-\mathrm{T} 2$ & OPLL + OYL & improved & 9 & 11 & $3 \mathrm{Y} 1 \mathrm{Mo}$ \\
\hline 52 & M & $\mathrm{T} 5-\mathrm{T} 12$ & OPLL + OYL & improved & 2 & 4 & $4 \mathrm{Y} 5 \mathrm{Mo}$ \\
\hline
\end{tabular}

F: female; M: male; Y: year; Mo: month; C: cervical spine; T: thoracic spine; OPLL: ossification of the posterior longitudinal ligaments; OYL: ossification of the yellow ligaments

six points concerned with the upper extremities (Table 3 maximum score: 11 points).

The thickness of the ossification was also assessed using preoperative magnetic resonance imaging (MRI) and computed tomographic myelography (CTM), and was divided into thick, moderate, or thin type.

\section{Results}

For the 11 patients with OPLL only in the thoracic spine treated using anterior procedures, the clinical symptoms and JOA scores improved in nine, but were unchanged in the two patients, who had previously undergone a cervical laminectomy. Their mean JOA scores increased from 4.9 to 7 postoperatively.

Complications of anterior surgery included intraoperative cerebrospinal fluid (CSF) leakage (four cases), postoperative CSF fistulae (two cases), and recurrent laryngeal nerve paralysis. Intraoperatively, CSF fistulae were not easily controlled using a compressive technique of soft tissue adhesive, ie Biobond (Yoshitomi Pharmaceutical Industries Ltd., Osaka). Where CSF fistulae persisted postoperatively, following a week of lumbar spinal drainage, a further operation was performed. Recurrent laryngeal nerve paralysis, which occurred in the patient having the median sternotomy, ${ }^{2}$ recovered a few months after surgery on the vocal cords.

For the 11 patients with long continuous OPLL in the cervico-thoracic spine or OYL and OYL combined with OPLL in the thoracic spine treated with posterior techniques, clinical symptoms improved in all of 11 patients. Their mean JOA scores increased from 6.2 to 9 postoperatively. There also appeared to be no obvious advantage to either of the procedures employed.

Complications such as CSF leakage, CSF fistulae and recurrent laryngeal nerve paralysis, experienced in those approached anteriorly, were not detected following posterior procedures. 


\section{Case reports}

Case 1

A 66-year-old woman had complained of bilateral numbness of the lower extremities since 1990. Clinical symptoms gradually worsened and she could not walk 3 years later. MRI and CTM showed OPLL in the cervical and thoracic spine, and laminoplasty ${ }^{3}$ was performed between $\mathrm{C} 1$ and $\mathrm{T} 1$ in July, 1993. Numbness below the level of $\mathrm{T} 7$ and urinary incontinence continued after the operation. MRI and CTM after laminoplasty demonstrated anterior compression of the spinal cord between $\mathrm{T} 3$ and $\mathrm{T} 7$ (Figure 1). Therefore, anterior decompression was performed from $\mathrm{T} 3$ to $\mathrm{T} 7$ using a transthoracic approach, and bone graft using a piece of fibula was carried out. Postoperative CT showed sufficient decompression of the spinal cord and a postoperative radiogram showed the grafted bone union (Figures 2 and 3). The clinical symptoms slightly improved and the JOA score increased from 2 to 3 .

Table 3 The Japanese Orthopaedic Association (JOA) score system for evaluation of cervical myelopathy

1. Motor function of upper extremity

0 points unable to feed oneself using chopsticks or spoon

1 point able to eat with spoon, but not with chopsticks

2 points able to eat with chopsticks, but difficult 3 points independent eats using chopsticks, though awkward

4 points normal

2. Motor function of lower extremity

0 points unable to walk

1 point need cane or aid on flat floor

2 points need cane or aid on stairs

3 points able to walk without cane or aid, but limited

4 points normal

3. Sensory disturbance

A. Upper extremities

$\begin{array}{ll}0 \text { points } & \text { apparent sensory loss } \\ 1 \text { point } & \text { minimal sensory loss }\end{array}$

2 points normal

B. Lower extremities

0 points apparent sensory loss

1 point minimal sensory loss

2 points normal

C. Trunk

0 points apparent sensory loss

1 point minimal sensory loss

2 points normal

4. Bladder function

0 points urinary retention (overflow incontinence)

1 point severe dysuria (sense of retention or retardation)

2 points mild dysuria (protraction)

3 points normal
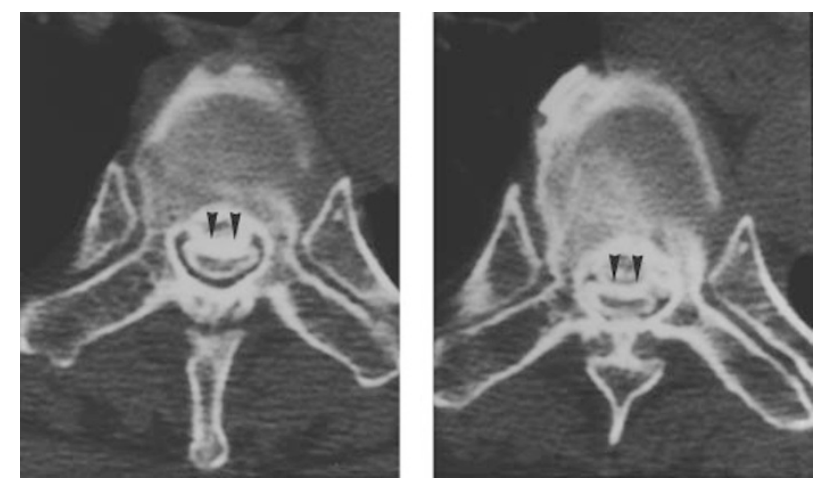

Figure 1 (a) Case 1: A 66-year old woman with OPLL in the cervical and the thoracic spine. CTM at the level of T3/4 (arrow heads indicate OPLL). (b) CTM at the level of T5/6 (arrow heads indicate OPLL)
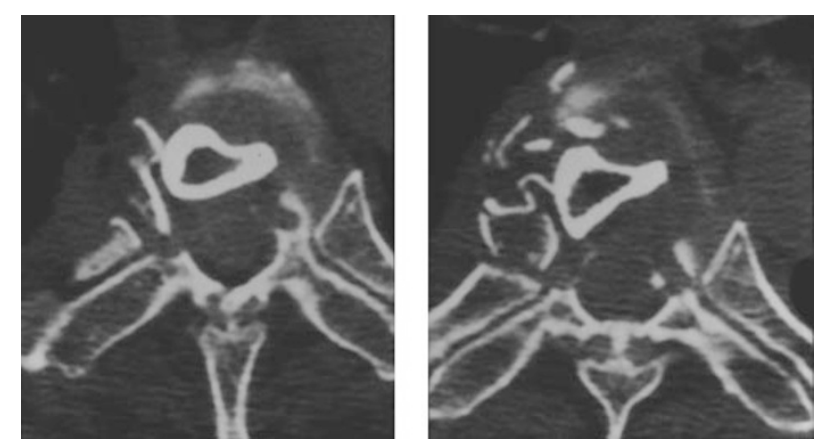

Figure 2 (a) Case 1: A 66-year-old woman with OPLL in the cervical and the thoracic spine. CT at 1 year after the operation at T3/4. (b) CT at 1 year after the operation at T5/6

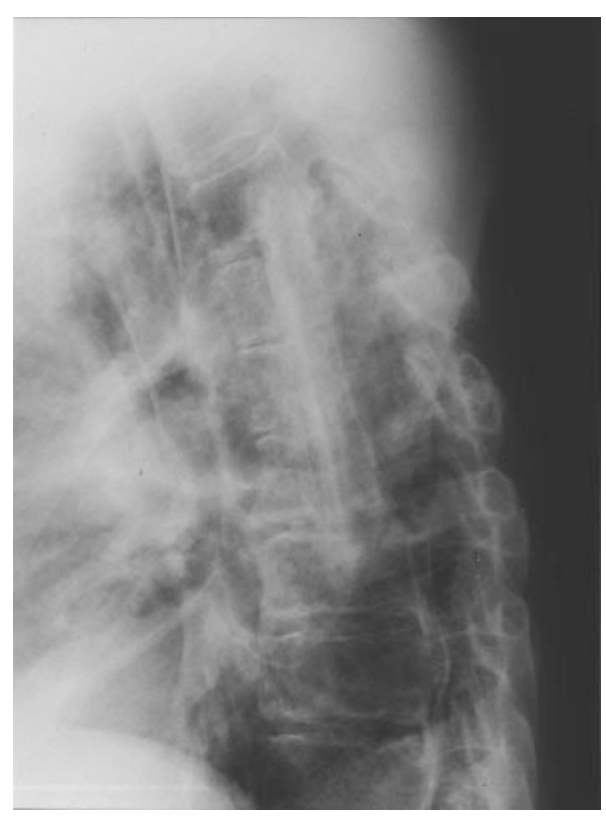

Figure 3 Case 1: A 66-year-old woman with OPLL in the cervical and the thoracic spine. Radiogram at 1 year after the operation 
Case 2

A 56-year-old man complained of gait disturbance and weakness of both lower extremities. Preoperative MRI and CTM showed OPLL in the cervical spine and T1T3 OYL. Laminoplasty was performed between $\mathrm{C} 1-$ C7 and laminectomy between T1-T3 were performed (Figure 4a,b, Figure 5). Although clinical symptoms improved postoperatively, the JOA score only increased from 10 to 11 .

\section{Case 3}

A 52-year-old man presented with the gradual onset of numbness and weakness of the lower extremities. MRI and CTM showed anterior thoracic T8-T9 cord compression due to OPLL and dural compression between T9-T12 by OYL (Figures 6 and 7). Laminoplasty between $\mathrm{T} 8$ and $\mathrm{T} 12$ and anterior decompression through a posterior approach at T8T9 were performed (Figure 8). The patient's JOA score increased postoperatively, but only from 2 to 4 .
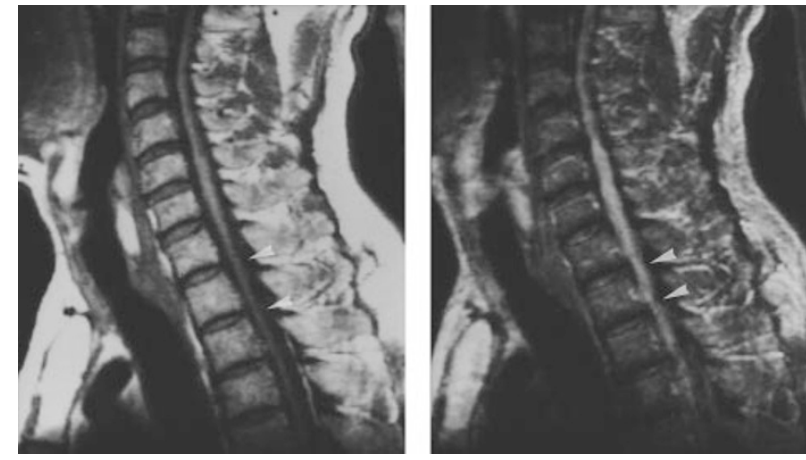

Figure 4 (a) Case 2: A 56-year-old man with OPLL in the cervical spine and OYL at the level of T1-T3. MRI on T1weighted image (arrow heads indicate OYL at T1-T3). (b) MRI on T2-weighted image (arrow heads indicate OYL at $\mathrm{T} 1-\mathrm{T} 3)$
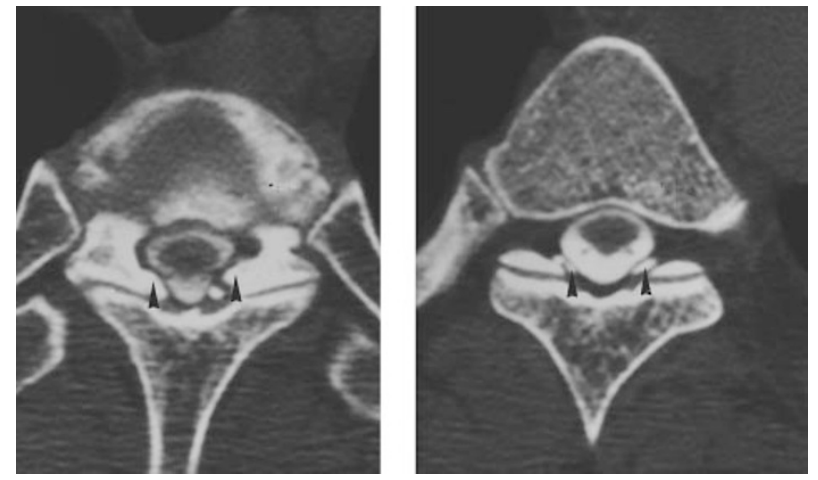

Figure 5 (a) Case 2: A 56-year-old man with OPLL in the cervical spine and OYL at the level of T1-T3. (b) CTM at the level of T3 (arrow heads indicate OYL)

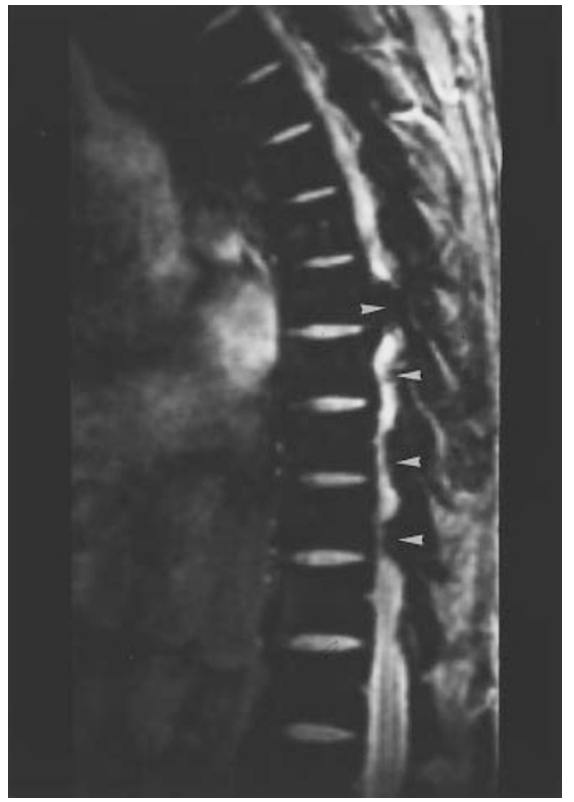

Figure 6 (a) Case 3: A 52-year-old man with OPLL at T8T9 and OYL at T9-T12. MRI on T2-weighted image in the thoracic spine (arrow heads indicate OPLL and OYL)
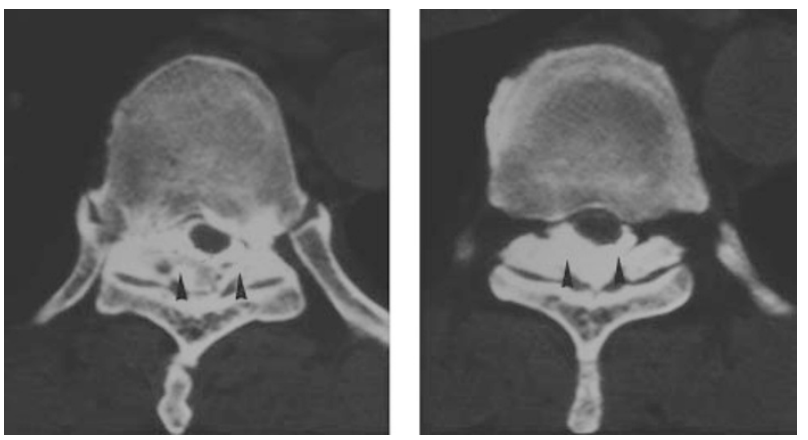

Figure 7 (a) Case 3: A 52-year-old man with OPLL at T8T9 and OYL at T9-T12. (b) CTM at the level of T11 (arrow heads indicate OYL)
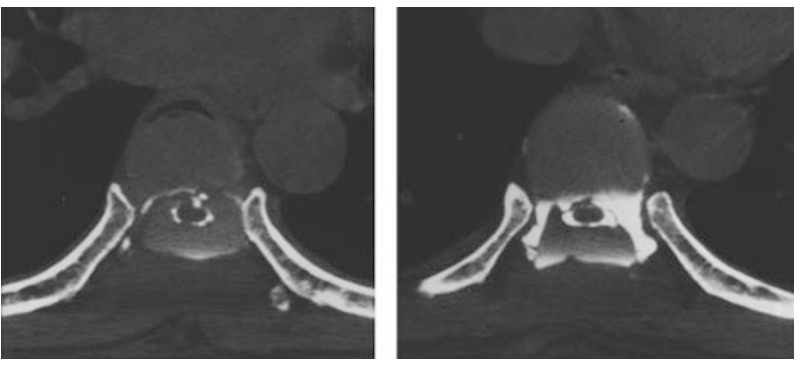

Figure 8 (a) Case 3: A 52-year-old man with OPLL at T8T9 and OYL at T9-T12. Postoperative CTM at the level of T8/9. (b) Postoperative CTM at the level of T10/11 


\section{Discussion}

Ossification of spinal ligaments, such as OPLL and OYL in the thoracic spine, is usually asymptomatic when lesions are small and thin and there is no cord compression. However, once myelopathy in the thoracic and cervico-thoracic spine appears due to OPLL, OYL and combination of both, conservative management is not effective and surgical treatments are required. Thoracic surgical approaches are divided into predominantly anterior and posterior techniques. ${ }^{4-9}$ Anterior procedures ${ }^{10}$ include the transthoracic approach, ${ }^{11}$ median sternotomy, ${ }^{2}$ transsternal approach, ${ }^{12}$ anterior decompression through the posterior approach ${ }^{13}$ and Micheli approach, ${ }^{14}$ while posterior techniques include the laminectomy. ${ }^{15}$ When an operative approach is selected, the type and location of compression, its form and extent, and the degree of thoracic kyphosis must be taken into consideration.

Anterior lesions, such as OPLL in the upper thoracic spine, may be decompressed using either anterior or posterior procedure. However, Hanakita et $a l$ suggested that laminectomy was generally ineffective for the management of thoracic myelopathy and occasionally precipitated clinical worsening especially in the presence of predominant anterior OPLL pathology. Stillerman and Weiss ${ }^{16}$ observed that laminectomy used to treat thoracic disc herniations led to poor results and therefore was not a suitable approach for anterior thoracic lesions. Simeone et al ${ }^{17}$ also reported that posterior procedures for anterior thoracic lesions were quite dangerous.

Subsequently, anterior procedures were chosen to address upper thoracic OPLL. For the upper thoracic spine, the median sternotomy and transsternal approaches were employed. However, for long continuous OPLL extending from the upper cervical spine to the thoracic spine, posterior procedures were more suitable than anterior alternatives. For patients with anterior lesions, anterior transthoracic approaches should be selected.

Furthermore, anterior lesions of the middle and lower thoracic spine should be decompressed anteriorly. This is feasible as the spinal cord in these regions is more anterior due to the thoracic kyphosis. ${ }^{18}$ Consequently, anterior procedures are suitable for OPLL at any level of the thoracic spine without regard to the form and extent of the lesions except long continuous OPLL in the cervico-thoracic spine.

Posterior lesions of the spinal cord, such as OYL, can be easily decompressed at any level of the thoracic spine using posterior procedures.

Combined lesions of OPLL and OYL are also usually decompressed using posterior procedures. However, in patients with large and/or thick OPLL compressive lesions, both anterior and posterior procedures will often be necessary to achieve adequate cord decompression.
There were no obvious differences in postoperative results noted for the 22 patients having either anterior or posterior surgery. Although clinical symptoms were improved in 20 patients, the improvement was often minimal. Clinical symptoms were unchanged in two patients who showed deterioration of neurological symptoms after a cervical laminectomy. Their unfavorable outcome showed that the surgical treatment in the thoracic and cervico-thoracic spine was not sufficient for a patient with deteriorated neurological symptoms after the operation in the upper level. At the present time, we have not yet attempted the neurophysiological tests such as evoked potential studies. We will attempt them in the near future, because it must be necessary to decide the decompressive levels for myelopathy in the thoracic and cervico-thoracic spine.

In conclusion, it is critical to choose appropriate surgical procedure when addressing OPLL and/or OYL contributing to myelopathy in the thoracic and cervico-thoracic spine, and CTM and myelo-CT studies are useful when the surgical procedure is selected.

\section{Acknowledgements}

We thank Jitsuhiko Shikata, MD, Department of Orthopaedic Surgery, Kyoto City Hospital, Yasutaka Matsuda MD and Hiroshi Tada, MD, Department of Orthopaedic Surgery, Faculty of Medicine, Kyoto University, for clinical assistance.

\section{References}

1 Yonenobu K et al. Thoracic myelopathy secondary to ossification of the spinal ligament. J Neurosurg 1987; 66: $511-518$.

2 Fang HS, Ong GB, Hodgson AR. Anterior spinal fusion: the operative approaches. Clin Orthop 1964; 35: 16-21.

3 Hirabayashi K, Watanabe K, Wakano K, et al. Expansive opendoor laminoplasty for cervical spinal stenotic myelopathy. Spine 1983; 8: $693-699$.

4 Dohn DF. Thoracic spinal cord decompression: Alternative surgical approaches and basis of choice. Clin Neurosurg 1980; 27: $611-623$.

5 Epstein NE. Ossification of the posterior longitudinal ligament; Diagnosis and surgical management. Neurosurgery 1992; Q2: $223-241$

6 Hanai $\mathrm{K}$ et al. Anterior decompression for myelopathy resulting from ossification of the posterior longitudinal ligament. $J$ Bone Joint Surg 1982; 64-B: $561-564$

7 Patterson Jr RH, Arbit E. A surgical approach through the pedicle to protruded thoracic discs. J Neurosurg 1978; 48: $768-$ 772 .

8 Stillerman CB, Weiss MH. Management of thoracic disc disease. Clin Neurosurg 1992; 38: $325-352$.

9 Turner PL, Webb JK. A surgical approach to the upper thoracic spine. J Bone Joint Surg 1987; 69-B: $542-544$.

10 Cauchoix J, Binet JP. Anterior surgical approaches to spine. Ann $R$ Coll Surg Eng 1957; 21: $237-243$.

11 Kojima T, Waga S, Kubo Y, Matsubara T. Surgical treatment of ossification of the posterior longitudinal ligament in the thoracic spine. Neurosurgery 1994; 34: 854-858.

12 Sundaresan N, Shah J, Joseph GF. A transsternal approach to the upper thoracic vertebrae. Am J Surg 1984; 148: 473-477. 
13 Ohtsuka $\mathrm{K}$ et al. The results of surgical treatment for thoracic myelopathy due to ossification of the posterior longitudinal ligament - Anterior decompression of the thoracic cord through the posterior approach. Clin Orthop Surg 1988; 23: 467-472.

14 Micheli LJ, Hood RW. Anterior exposure of the cervicothoracic spine using a combined cervical and thoracic approach. $J$ Bone Joint Surg 1983; 65-A: $992-997$.

15 Yamamoto I et al. Thoracic spinal stenosis: Experience with seven cases. J Neurosurg 1988; 68: $37-40$

16 Stillerman CB, Weiss MH. Principles of surgical approaches to the thoracic spine. In: Neurosurgical Treatment of Disorders of the Thoracic Spine. Park Ridge: IL, AANS, 1992: pp 1-18.

17 Simeone FA, Rashbaum R. Transthoracic disc excision. In: Operative Neurological Techniques. New York: Grune \& Stratton, 1982: pp 1259-1268

18 Perot Jr PL, Munro DD. Transthoracic removal of midline thoracic disc protrusions causing spinal cord compression. $J$ Neurosurg 1969; 31: 452-458. 